\title{
A COMPARATIVE STUDY REGARDING PAIN PERCEPTION AMONG MALES AND FEMALES OF UNIVERSITY STUDENTS IN PUNJAB, SINDH \& BALOCHISTAN
}

\author{
Saiyida Tasmeera, Tanvir Akhtar, Shoaib Kiani*, Yasir Masood Afaq**, Naveeda** \\ Foundation University, Islamabad Pakistan, *Personnel Admiration Directorate, GHQ Rawalpindi Pakistan, ${ }^{* *}$ MYMA Communication, Islamabad Pakistan, \\ ${ }^{* * *}$ Quaid-e-Azam University, Islamabad Pakistan
}

\begin{abstract}
Objective: To compare gender differences on pain perception in Pakistani culture.

Study Design: Cross-sectional study.

Place and Duration of Study: Public and private universities of Rawalpindi, Islamabad, Gujrat, Karachi, and Quetta, from Mar to May 2019.

Methodology: A scale of religious identity was developed $(n=300)$. Additionally, participants $(n=240)$ were assigned to pain condition and no pain condition (control condition). Pain condition made them aware of headaches, while the control condition made them aware of death. Participants in both conditions were informed to jot down their emotions. They were also provided Positive and Negative Affect Schedule (PANAS), a distractor task in the form of a story followed by a religious identity scale to compare the difference in percentages of males and females in pain and no pain perception on religious identity.

Results: The alpha reliability of the religious identity scale was 0.60 depicting a moderately internally consistent scale. Furthermore, the findings of the present study showed significant gender differences on pain perception. Mean values indicated high score for females $(226.39 \pm 28.43)$ than males $(216.39 \pm 31.73)$ in pain condition and similar was the case of no pain condition for females $(130.81 \pm 23.27)$ and males $(133.35 \pm 20.06)$. Whereas, males $33(63.04 \%)$ were high on religious identity as compared to females $35(56.06 \%)$ in pain condition whereas females $34(50.84 \%)$ were high in no pain condition on religious identity as compared to males $22(37.31 \%)$.

Conclusion: Findings suggested that significant differences exist between males and females in perceiving pain.
\end{abstract}

Keywords: Gender, Pain, Perception, Psychosocial, Religious identity.

How to Cite This Article: Tasmeera S, Akhtar T, Kiani S, Afaq YM, Naveeda. A Comparative Study Regarding Pain Perception Among Males and Females of University Students in Punjab, Sindh \& Balochistan. Pak Armed Forces Med J 2021; 71(5): 1637-1641. doi: https://doi.org/10.51253/pafmj.v71i5.3712

This is an Open Access article distributed under the terms of the Creative Commons Attribution License (https://creativecommons.org/licenses/by-nc/4.0/), which permits unrestricted use, distribution, and reproduction in any medium provided the original work is properly cited.

\section{INTRODUCTION}

Shared concepts among appraisal theories suggest that cognitionemotion, as well as pain perception, are cognitive mechanisms that underlie how people respond to adversity. ${ }^{1}$ However, the sound measurement of the intensity of pain is important for successful diagnosis, assessment and therapy. According to Mordeniz, pain is a conscious experience rooted in memories, emotions, thinking, injury and genetics. In medical terms, pain is caused due to tissue damage so its perception can range from mild to severe, agonizing discomfort and manifesting subjective content of consciousness. It is a mental experience at different degrees of consciousness that is based on the intermingling of chemical, biological, psychological, physiological, soceconomical, cultural, ethnic backgrounds and cognitive factors. ${ }^{2}$ Park emphasizes that the significance of context, expectations, and distractions play a role in pain percep-

Correspondence: Dr Saiyida Tasmeera, PhD Scholar, Foundation University, Islamabad Pakistan

Received: 07 Jan 2020; revision received: 21 Feb 2020; accepted: 28 Feb 2020 tion despite the bodily harm. Furthermore, reasons such as traditions and expectations also play an important role in how a person perceives pain. Traditional gender roles are well defined in the collectivistic cultural environment of Pakistan. Expression of pain and pleasure is also seen through a lens of gender-appropriate behaviour. This gives an insight into how pain receptors are not the only stimulations of what we see and hear rather deep psychological factors are also at play for instance our perceptions are affected by our interests and desires. ${ }^{3}$ The most profound element of Pakistani culture having an impact on ethnicity, norms, values and at large on every form of perception is religion. Religion and culture are intertwined in Pakistan. Religion induces a concept of patience in the face of emotional and physical pain. Pain management has its roots in ritualistic practices of religion. The more an individual affiliates with his religious identity the less pain is perceived. Perceptions of good and bad to pain or peace are hugely influenced by religious culture and not only by the physicality of things. ${ }^{4}$ 
Whether a culture is patriarchal or matriarchal, the portrayal of strength and leadership roles with respect to gender and economic dependency of males or females has its impact on pain perception for example according to one study, Asian participants with chronic back pain reported less dysfunction than Caucasian participants this may reflect stoicism and a preference for minimizing pain in Asian cultures. ${ }^{5}$ And another study showed that the daily functioning of US adults with chronic lower back pain is negatively affected more than those without chronic lower back pain. ${ }^{6}$ Alternatively, there is greater support from family and friends for individuals within Asian collectivistic cultures. ${ }^{7}$

Many studies are supporting male and female pain perception differences, the processing of pain is biological as well as a psychosocial phenomenon. Comparing the pain coping strategies between males and females stereotypical gender roles have a contribution to differences in pain expression. Variations in social exposure may explain the differences in gender roles which in turn explains why pain is perceived differently. ${ }^{8}$ According to Palmeira, Ashmawi, and Posso, females report more severe and long-lasting pain along with disease processes than males. Moreover, pain perception is greatly influenced by a complex interaction between biological (genetic, gonadal hormones, and pain circuitry pathways) and psychosocial variables (depression, anxiety, gender role expectancies, culture and appraisal related to pain). ${ }^{9}$ It is also shown that women experience greater clinical pain, lower tolerance and more sensitivity and distress to experimentally induced pain as compared to men. ${ }^{10}$ Sex differences in response to opioid treatment revealed inconsistent results, however, the aetiology of these inconsistencies is not clear. It is, therefore, conceivable that this literature can be revisited comprehensively because possible multifaceted factors like neuroanatomical, hormonal, neuroimmunological, psychological, social, cultural aspects and other comorbidities seem to be associated. ${ }^{10}$ Hence, the primary goal of the study is to assess gender differences in pain perception among Pakistani participants on whom various psychosocial and culturally religious factors are at play.

\section{METHODOLOGY}

This cross sectional study was conducted in the public and private universities of Rawalpindi, Islamabad, Gujrat, Karachi and Quetta, from March to May, 2019. Ethical approval to conduct this study was granted by the Ethical Review Committee of Foundation
University Rawalpindi Campus Ref No FURC/CO/ Acad/ERC/Spring-2017/924. In addition, informed consent was taken from the participants and were ensured regarding privacy and confidentiality to the matters and their right to withdraw at any time. Participants were debriefed about the true nature of the research at the end.

As the phase-I of the study ; Religious Identity Scale (RIS) development included review of the literature, which directed the development of item pool. Experts from related professions reviewed the literature. On the basis of key indicators, 14 items were developed the items were in English language. The researcher and the supervisor of the research study critically reviewed the items that was followed by the review of the English language expert.

Inclusion Criteria: Both male and female students from English department of a public university were included through convenient sampling $(n=300)$.

Exclusion Criteria: Non-consenting individuals were excluded.

Comrey recommended the range of 200-300 as appropriate for factor analysis. ${ }^{11}$ At the onset informed consent was taken from the students. Their confidentiality and anonymity was maintained. The scale was administered in 30-40 minutes. It was informed that their honest responses will help in the development of a scale that will be part of research.

For Phase-II of the study, sample size was estimated by consulting meta-analyses of over 277 studies of MS effect sizes.11-13 Based on an average observed effect size of $g=0.57$ (interpreted similar to Cohen's d), an a priori power analysis (G*Power), ${ }^{14}$ prescribed a minimum of 30 participants per each MS and comparison/control condition in each study. Therefore, sample of 240 participants, including both males $(n=106)$ and females $(n=134)$, was recruited from different public and private universities of Pakistan through random sampling. Individuals willing to give informed consent and affiliated with different institutions around Pakistan with a good understanding of English \& Urdu language, having an age range between 18-37 years were recruited as participants. However, individuals with any disability, psychological problem and trauma were not included in the current study.

Participants were told that the present study intends to investigate the different aspects of memory to protect the study from the confounds of participant bias. After taking informed consent and demographic 
information, participants underwent the following procedure. Experimental design as a successful method has been used over decades and in different previous studies. ${ }^{15,16}$ By following this specific method, participants were assigned to pain condition and no pain condition (control condition). Pain condition made them aware of a headache by asking participants, "Please briefly describe the emotions that the thought of headache arouses in you" and "Jot down, as specifically as you can, what you think happens to you as you experience headache physically." While control condition made participants aware of death by asking participants, "Please briefly describe the emotions that the thought of your own death arouses in you" and "Jot down, as specifically as you can, what you think happens to you as you physically die." (Mortality salience manipulation). Further, participants completed the Positive and Negative Affect Schedule (PANAS), ${ }^{17}$ using hard copy and paper pen. After that, participants completed a distracter task, because prior research demonstrates that people orient toward direct healthrelated responses when death-thought is in focal conscious awareness, but toward indirect cultural belief responses when death-thought is moved outside conscious awareness. ${ }^{16}$ (Affect and distracter tasks). The participants were then measured on Religious Identity Scale (RIS).

Factorial structure of the items of the scale was assessed by doing a principle component analysis and reliability was calculated through Cronbach's alpha. Comparison of dependent variable (pain perception) on independent variable (gender) was conducted by running a t-test on Statistical Package for Social Sciences (SPSS) version 23.

\section{RESULTS}

Out of 300 Students 149 (49.6\%) were males and $151(50.3 \%)$ females. The mean age was $21.23 \pm 1.91$ years from 18 to 30 years.

The factorial structure of the initial batch of 14 items was assessed by conducting a non-orthogonal (direct oblimin) principle component analysis. After the investigation of the inter-item correlation matrix, 4 items were excluded due to their low inter-item correlation. For the remaining 10 items, the KaiserMeyer-Olkin measure $(\mathrm{KMO}=0.61)$ verified sampling adequacy for the analysis; Bartlett's test of sphericity $x^{2}(91)=442.79, p<0.001$, indicated that correlations between items were significantly large for PCA, and, two-component had an Eigenvalue greater than 1, explaining $28.53 \%$ of the variance. After investigation of these items, the first set of items loaded onto factor-1 was named "Religious Affiliation" and factor 2 was named as "Religious Outlook".

Table-I showsx item corrections through principal component analysis and Cronbach's alpha. The correction factor is 0.60 that is less than 0.75 hence the cut-off scores of religious identity is defined by the median value (59.7). ${ }^{12}$

For phase-II of the study, we had a total of 240 participants, including both males $106(44.1 \%)$ and females 134 (55.8\%) whose age range was 18-37 years with a mean of $21.23 \pm 0.91$. Participants were randomized to eight conditions using block randomization, with an equal number of allocations to all conditions (i.e. $n=30$ per condition). Table II shows significant gender diffe-rences on pain perception. Mean values indicate high score for females than males $p=0.02$.

Table-III shows males 33 (63.04\%) were high on religious identity as compared to females 35 (56.06\%)

Table-I: Summary of principle component analysis $(n=300)$.

\begin{tabular}{l|c|c}
\hline Items & Factor 1 & Factor 2 \\
\hline Namaz identifies a true Muslim & 0.529 & \\
\hline $\begin{array}{l}\text { Saying five times prayers in Masjid } \\
\text { (mosque) represents a good Muslim }\end{array}$ & 0.568 & \\
\hline $\begin{array}{l}\text { Every Muslim should have a spirit of } \\
\text { jihad }\end{array}$ & 0.498 & \\
\hline $\begin{array}{l}\text { Powerful Islamic empires sustained } \\
\text { due to jihad }\end{array}$ & 0.454 & \\
\hline $\begin{array}{l}\text { Purdah (modest covering / dressing) } \\
\text { must be observed by every Muslim } \\
\text { woman. }\end{array}$ & 0.622 & \\
\hline $\begin{array}{l}\text { Purdah (modest covering / dressing) is } \\
\text { a sign of piety }\end{array}$ & 0.693 & 0.406 \\
\hline Beard represents a Muslim man & \multicolumn{2}{|c}{0.603} \\
\hline Bearded men are regarded as terrorists & \multicolumn{2}{|c}{0.60} \\
\hline Bearded men are not always religious & 0.434 & 0.59 \\
\hline Namaz identifies a true Muslim & 16.36 & 12.176 \\
\hline$\%$ of Variance & 0.65 & 0 \\
\hline Total \% of Variance & \multicolumn{2}{|c}{0} \\
\hline a & & \\
\hline Total a &
\end{tabular}

Table-II: Independent Sample t-test results for gender on pain perception $(n=240)$.

\begin{tabular}{|c|c|c|c|}
\hline \multirow{2}{*}{ Variable } & Males (n=106) & Females $(n=134)$ & \multirow{2}{*}{$\begin{array}{c}p- \\
\text { value }\end{array}$} \\
\hline & Mean \pm SD & Mean \pm SD & \\
\hline $\begin{array}{l}\text { Pain } \\
\text { Perception }\end{array}$ & $217.92 \pm 30.43$ & $226.45 \pm 29.25$ & 0.02 \\
\hline
\end{tabular}

Table-III: Result of males and females on religious identity in pain and no condition.

\begin{tabular}{l|c|c}
\hline \multirow{2}{*}{ Gender } & \multicolumn{2}{|c}{ Religious Identity in Pain } \\
\cline { 2 - 3 } & Yes & No \\
\hline Male $(\mathrm{n}=52)$ & $33(63.04)$ & $22(37.31)$ \\
\hline Female $(\mathrm{n}=62)$ & $35(56.06)$ & $34(50.84)$ \\
\hline
\end{tabular}


in pain condition whereas females 34 (50.84\%) were high in no pain condition on religious identity as compared to males 22 (37.31\%).

\section{DISCUSSION}

We hypothesized that a difference exists in the pain perception of females as compared to males due to psychosocial factors like gender and religion. To ascertain this hypothesis a culturally valid scale on Religious Identity was developed. Among other factors, religion acts as a neutralizer in unpleasant incidents experienced by Middle Eastern Muslims as found by Suhail et al. ${ }^{18}$ Popular psychological practices studied in 2017 were said to stem from Buddhist meditation practices which traditionally have been a part of religious awakening. ${ }^{4}$ There are similarities between religious practices and placebo effects. ${ }^{14-19}$ The working behind the placebo effects start the body's own coping strategies and healing. In amalgamation, lifestyle, social support, and placebo effects thus produce both actual and apparent health effects of religiosity. This may have played an important role in the evolution and diffusion of religion through two main pathways. First, any actual constructive health effects of religiosity would have given a direct biological advantage. Second, any professed health effects, both positive and negative, would further have had an exclusive selling point for 'religiosity' per se. Hence, religiosity seems to have played with both actual and perceived biological and cultural pathways ${ }^{4}$. This was ascertained in this study by comparing the percentage of males and females falling on the upper end of the cut-off score of the Religious Identity Scale (RIS).

In terms of gender, the prevalence of pain is female-oriented it might be due to the reason that in comparison to males, females seek more health care, are more vulnerable to health issues that induce more pain, and lastly, they are also less pain tolerant. In addition, the biological sex differences such as pain pathways (ascending pain transmission pathways, descending pain modulation pathways) or other psychological processes may affect pain sensitivity in women. ${ }^{20}$

According to Werner, Steihaug, and Malterud, women confront different kinds of challenges and are tangled in a set of gender norm expectations. ${ }^{21}$ Consequently, the overburden of responsibility women face from family and at home might be a hindrance for women in recovery. The study illustrates that in comparison with males, females experience more clinical pain and show heightened sensitivity to experimentally induced pain. ${ }^{22}$ The factors behind the gender differences in the experience of pain are multiple and complicated; for example, the gonadal hormone level has a significant effect on pain perception and analgesic response in women. During the luteal phase women, experience more pain while estrogen acts as an antagonist providing long-term pain relief. ${ }^{22}$ According to Samulowitz, Gremyr, Eriksson, and Hensing's study in 2018 pain response patterns that are deepseated in young boys and girls for a long time period become set norms of gender in the society. Consequently, boys are trained to be rough, strong and pain tolerant. However, girls are schooled to be soft and delicate, cautious and to report their distress. ${ }^{23}$ Pain perception is also influenced by cultural and traditional expectations; the stereotypical roles consist of interests, behaviour and life choices for each gender. It is illustrated that men perceive pain as a threat to their masculinity and most of the time, refuse to accept it; they either ignore it or do not seek medical assistance. ${ }^{23}$ Additionally, men remain in denial and do not let the pain affect their daily functioning. They do not prefer to set forth their weakness in public. ${ }^{24}$

According to Fillingim, gender does not directly affect pain; however, gender differences in pain depict the influence of another biological and psychosocial phenomenon such as coping, hormones, and inflammatory responses. On the other hand, the relationship between biological markers and pain might be examined because it provides not only individual differences but also a potential mechanism that significantly affects pain. It is believed that demographic constructs do not directly influence pain, rather they illustrate individual differences because they can be assessed easily and provide information about the huge outsized population that might be at risk for experiencing increased pain. ${ }^{25}$

It is apparent that both men and women use different coping strategies to overcome pain. Women might be emotionally oriented; however, men focus on sensory aspects; this study showed that females were high in no pain condition on religious identity as compared to males because the emotional affiliation with religion helps them cope with pain hence more women were in no pain condition. The combination of emotion and pain is negative and might lead to intense pain. Fillingim also suggested that pain responses are based on unique and multiple factors including demographics, psychosocial factors, genetics, stress and pain etc. All these factors cause a variety of experiences of 
pain that can be completely unique to an individual experiencing pain at that time. ${ }^{24}$

\section{LIMITATION OF STUDY}

The demographics of the study were limited to gender and religion: future studies should also consider other important demographic variables such as socioeconomic status, family background and other cultural aspects.

\section{CONCLUSION}

The findings of the current study are in line with previous literature that females and males experience pain differently but the percentage might differ taking into account the variety of influences affecting the perception of each. Moreover, it was established that religious attribution also plays an important role in pain perception. Hence, other psychological factors will further be explored as the impact on pain perception with reference to psychosocial variables has been established.

\section{Conflict of Interest: None.}

\section{Authors' Contribution}

ST: Conducting the experiment, literature review, data analysis, main script writing. TA: Supervising literature review, data analysis, discussion and conclusion. SK: Final version proofreading, editing and reference writing. YMA: Assisting experimentation around Pakistan. N: Reference writing.

\section{REFERENCES}

1. Yao ZF, Hsieh S. Neurocognitive Mechanism of Human Resilience: A Conceptual Framework and Empirical Review. Int J Environ Res Public Health 2019; 16(24): 5123-5128.

2. Mordeniz C. Pain perception within consciousness. Neuroquantol 2016; 1(2): 439-446.

3. Park T. Pain, Perception, and the appearance-reality distinction. Philos Ana 2017; 38(2): 205-237.

4. Lindahl JR, Fisher NE, Cooper DJ, Rosen RK, Britton WB. The varieties of contemplative experience: a mixed-methods study of meditation-related challenges in Western Buddhists. PLoS One 2017; 12(5): e0176239.

5. Brena SF, Sanders SH, Motoyama H. American and Japanese chronic low back pain patients: cross-cultural similarities and differences. Clin J Pain 1990; 6(2): 118-124.

6. Shmagel A, Foley R, Ibrahim H. Epidemiology of chronic low back pain in us adults: data from the 2009-2010 national health and nutrition examination survey. Arthritis Care Res (Hoboken). 2016; 68(11): 1688-1694.

7. Liao KY, Henceroth M, Lu Q, LeRoy A. Cultural differences in pain experience among four ethnic groups: a qualitative pilot study. J Behav Health. 2016; 5(2): 75-81.
8. Rokyta R, Yamamotová A. Sex differences in pain perception and interpretation. Act Nerv Super Rediviva 2013; 55(3): 125-134.

9. Palmeira CC, Ashmawi HA, Posso Ide P. Sex and pain perception and analgesia. Rev Bras Anestesiol 2011; 61(6): 814-828.

10. Nasser SA, Afify EA. Sex Differences in pain and opioid-mediated antinociception: modulatory role of gonadal hormones. Life Sci 2019; 237(2): 116926.

11. Comrey AL. Factor-analytic methods of scale development in personality and clinical psychology. J Consult Clin Psychol 1988; 56(5): 754-761.

12. Barua A, Kademane K, Gubbiyappa KS, Verma RK, Iqbal MS, AL-Dubai SAR. A tool for decision-making in norm-referenced survey questionnaires with items of continuous variables. Int J Collab Res Intern Med Public Health 2013; 3(11): 1109-1118.

13. Burke BL, Martens A, Faucher EH. Two decades of terror management theory: a meta-analysis of mortality salience research. Pers Soc Psychol Rev 2010; 14(2): 155-195.

14. Faul F, Erdfelder, Buchner A, Lang AG. statistical power analyses using $G^{*}$ power 3.1: tests for correlation and regression analyses. Behav Res Method 2009; 41(4): 1149-1160.

15. Rosenblatt A, Greenberg J, Solomon S, Pyszczynski T, Lyon D. Evidence for terror management theory: $i$. the effects of mortality salience on reactions to those who violate or uphold cultural values. J Pers Soc Psychol 1989; 57(4): 681-690.

16. Pyszczynski T, Solomon S, Greenberg J. Thirty years of terror management theory: from genesis to revelation. Adv Exp Soc Psychol 2015; (52): 1-70.

17. Watson D, Clark LA. The PANAS-X: Manual for the Positive and Negative Affect Schedule - Expanded Form. Iowa: University of Iowa; 1999, [Internet] Available at: https://www.midss.org/ content/panas- $x$-manual-positive-and-negative-affect-schedule (Accessed on May 15, 2019)

18. Suhail K, Akram S. Correlates of death anxiety in Pakistan. Death Stud 2002; 26(1): 39-50.

19. Lindenfors P. Divine Placebo: health and the evolution of religion. Hum Ecol 2019; 47(2): 1-7.

20. Mogil JS. Sex Differences in pain and pain inhibition: multiple explanations of a controversial phenomenon. Nat Rev Neurosci 2012; 13(12): 859-866.

21. Werner A, Steihaug S, Malterud K. Encountering the continuing challenges for women with chronic pain: recovery through recognition. Qual Health Res 2003; 13(4): 491-509.

22. Paller CJ, Campbell CM, Edwards RR. Sex-based differences in pain perception and treatment. Pain Med 2009; 10(2): 289-299.

23. Samulowitz A, Gremyr I, Eriksson E, Hensing G. "Brave Men" and "Emotional Women": A theory-guided literature review on gender bias in health care and gendered norms towards patients with chronic pain. Pain Res Manag 2018; 2018(2): 1-14.

24. Nielsen DS, Brixen K, Huniche L. Men's experiences of living with osteoporosis: focus group interviews. Am J Men's Health 2011; 5(2): 166-176.

25. Fillingim RB. Individual differences in pain: understanding the mosaic that makes pain personal. Pain 2017; 158(1): 11-18. 